ORIGINAL ARTICLE

\title{
Determinants of inconsistent condom use with female sex workers among men attending the STD clinic in Singapore
}

\author{
S Wee, M E Barrett, W M Lian, T Jayabaskar, K W R Chan
}

See end of article for authors' affiliations

Correspondence to:

Correspondence to:
Sharon Wee, Department of Community,

Occupational and Family

Medicine (MD3), Faculty of

Medicine, National

University of Singapore,

16 Medical Drive

Singapore 117597;

cmewees@nus.edu.sg

Accepted for publication 26 February 2004

Background/objectives: Female sex workers and their male clients have been identified as risk groups for the transmission of STDs and HIV. Behavioural interventions targeting clients need to address inconsistent condom use among them. The aim of the study is to assess the sociodemographic, behavioural, and psychological factors associated with inconsistent condom use among clients of sex workers.

Methods: 229 male patients attending the STD clinic in Singapore who reported paying for sex in the previous 6 months were interviewed. Response rate was $91 \%$.

Results: Overall, $45 \%$ used condoms inconsistently; these clients were more likely to have poor STD knowledge, visit sex workers five or more times in the past 6 months, have lower self efficacy, less favourable social norms for condom use, and more likely to forget condom use when intoxicated (alcohol impaired decision making).

Conclusions: Behavioural interventions for clients need to improve STD/HIV transmission knowledge and focus on improving client's self efficacy in using condoms.

U nprotected sex between sex workers and their clients is one of the behaviours that is associated with the highest risk of HIV infection in Asia. ${ }^{12}$ In Singapore, the proportion infected through heterosexual transmission (mainly from commercial sex) has increased from $29.4 \%$ in 1990 to $76.4 \%$ in $2001 .^{3}$ A population based survey of Singaporeans' sexual behaviour in 1992 found that 72.4\% of clients reported that sex with sex workers was unprotected or partially protected by condoms. ${ }^{4}$ Clients serve as a bridge for sexually transmitted diseases (STDs) and HIV transmission to the mainstream population such as their wives or girlfriends. ${ }^{56}$ As abstinence and monogamy may not be realistic goals for this group, condom use is the only method to reduce infection. However, there is a scarcity of data on clients, and even less on their condom use behaviour.

Psychological theories can help explain behaviour and identify factors associated with condom use. Individuals are more likely to use condoms when they perceive the threat of AIDS to be serious and feel personally vulnerable to contracting it. They should also have high self efficacy in condom use and feel that it is an effective means of reducing HIV infection. In addition, attitudes towards condom use should be favourable and the perceived social norms for condom use are supportive. ${ }^{78}$ However, in situations where severity and vulnerability are high but self efficacy and response efficacy are low, maladaptive behaviours may be adopted instead (for example, "no matter what precautions I take I might still get AIDS"). ${ }^{9}$ Hence, the focus of this study is to assess the sociodemographic, behavioural, and psychological factors that may influence clients' inconsistent condom use with sex workers.

\section{METHODS}

\section{Participants}

Participants were recruited from the only public STD clinic in Singapore. Between December 2000 and May 2001, all male patients who reported paying for sex in the past 6 months were referred for face to face interview. Those attending the clinic for follow up treatment were excluded. A total of 235 clients were interviewed, the response rate was $91.1 \%$. There were six participants who engaged a sex worker for activities other than vaginal sex like oral sex or masturbation, and were excluded from this analysis, leaving a sample size of 229.

\section{Questionnaire measures}

The questionnaire was pilot tested for literacy and suitability for our local sample. This study reports results for one dependent variable, "inconsistent condom use with sex workers during the past 6 months." A respondent was classified as an inconsistent condom user if he did not use a condom at each and every visit to a sex worker. Sociodemographic variables included age, nationality, marital status, educational level, occupation, monthly income, alcohol consumption, and age of first sexual intercourse. Behavioural variables included number of visits to a sex worker in the past 6 months, sexual acts engaged in (vaginal or oral), and whether a condom was used. Participants were also asked, other than sex workers, if they had other sex partners (that is, wife, girlfriend, or casual partners) in the past 6 months. They were also asked if they had a previous STD infection. Participants were tested on their STD/HIV transmission knowledge and steps for correct condom use; scores were summed to form the STD knowledge and condom knowledge scales, respectively. Seven psychological variables were considered: perceived severity, perceived vulnerability, self efficacy, response efficacy, maladaptive behaviours, attitudes, and social norms. These were measured on Likert-type scales which were summed to yield scale scores. The score reflects the respondent's endorsement of the construct; with higher scores reflecting greater endorsement.

\section{Data analysis}

The Pearson $\chi^{2}$ was used to compare differences in proportions for categorical variables and Student's $t$ test for continuous variables. The non-parametric Mann-Whitney U test was used for continuous variables that were skewed. For multivariable analysis, the binary logistic regression model was applied. For a medium size relation between the dependent variable and seven independent psychological variables; with $\alpha=0.05$ and $\beta=0.2$, the rule of thumb is $N \geqslant$ $50+8 m$ (where $m$ is the number of independent variables). ${ }^{10}$ 
Table 1 Number (\%) of inconsistent condom users among clients according to sociodemographic, behavioural, and knowledge variables

\begin{tabular}{|c|c|c|c|c|c|}
\hline \multirow[b]{2}{*}{ Variable } & \multirow[b]{2}{*}{ Total } & \multicolumn{4}{|l|}{ Condom use } \\
\hline & & Inconsistent & & Consistent & \\
\hline \multicolumn{6}{|l|}{ Sociodemographic variables } \\
\hline Mean (SD) & 34.7 & 35.9 & $(10.00)$ & 33.7 & $(10.17)$ \\
\hline Median & 32 & 34 & & 31 & \\
\hline \multicolumn{6}{|l|}{ Nationality } \\
\hline Singaporean & 154 & 65 & (42.2) & 89 & (57.8) \\
\hline Others & 75 & 38 & $(50.7)$ & 37 & (49.3) \\
\hline \multicolumn{6}{|l|}{ Marital status } \\
\hline Never married & 132 & 60 & (45.5) & 72 & (54.5) \\
\hline Married & 97 & 43 & (44.3) & 54 & (55.7) \\
\hline \multicolumn{6}{|l|}{ Education } \\
\hline None or primary education & 50 & 33 & (66.0) & 17 & $(34.0)^{*}$ \\
\hline Secondary or higher & 179 & 70 & (39.1) & 109 & $(60.9)$ \\
\hline \multicolumn{6}{|l|}{ Occupation } \\
\hline Unskilled operators & 55 & 34 & (61.8) & 21 & $(38.2)^{*}$ \\
\hline Skilled operators & 75 & 37 & (49.3) & 38 & (50.7) \\
\hline Others & 99 & 32 & (32.3) & 67 & (67.7) \\
\hline \multicolumn{6}{|l|}{ Salary (Singapore \$) } \\
\hline$<2000$ & 135 & 71 & (52.6) & 64 & $(47.4)^{*}$ \\
\hline$\geqslant 2000$ & 94 & 32 & $(34.0)$ & 62 & $(66.0)$ \\
\hline \multicolumn{6}{|l|}{ Business trips } \\
\hline Yes & 53 & 17 & (32.1) & 36 & $(67.9)^{*}$ \\
\hline No & 176 & 86 & $(48.9)$ & 90 & (51.1) \\
\hline \multirow{2}{*}{\multicolumn{6}{|c|}{ Behavioural variables }} \\
\hline \multicolumn{2}{|l|}{ No of visits in the past 6 months } & & & & \\
\hline Median & 3 & 4 & & $2^{*}$ & \\
\hline $1-4$ & 161 & 59 & (36.6) & 102 & $(63.4)^{* *}$ \\
\hline$\geqslant 5$ & 67 & 44 & (65.7) & 23 & (34.3) \\
\hline \multicolumn{6}{|l|}{ Have regular sex worker } \\
\hline Yes & 34 & 21 & $(61.8)$ & 13 & $(38.2)^{*}$ \\
\hline No & 195 & 82 & (42.1) & 113 & $(57.9)$ \\
\hline \multicolumn{6}{|l|}{ Practise oral sex } \\
\hline Yes, use condom & 72 & 24 & (33.3) & 48 & $(66.7)$ \\
\hline Yes, didn't use condom & 63 & 31 & $(49.2)$ & 32 & $(50.8)$ \\
\hline No & 94 & 48 & (51.1) & 46 & $(48.9)$ \\
\hline \multicolumn{6}{|l|}{ Have other sex partners } \\
\hline Yes & 108 & 38 & (35.2) & 70 & $(64.8)^{*}$ \\
\hline No & 120 & 65 & (54.2) & 55 & (45.8) \\
\hline \multicolumn{6}{|l|}{ Previous STD infection } \\
\hline Yes & 82 & 46 & $(61.8)$ & 36 & $(38.2)^{*}$ \\
\hline No or don't know & 147 & 57 & (42.1) & 90 & $(57.9)$ \\
\hline \multicolumn{6}{|l|}{ Knowledge } \\
\hline \multicolumn{6}{|l|}{ STD knowledge } \\
\hline Poor $(<10)$ & 186 & 95 & (51.1) & 91 & $(48.9)^{* *}$ \\
\hline Good (10-11) & 43 & 8 & (18.6) & 35 & (81.4) \\
\hline \multicolumn{6}{|l|}{ Condom knowledge } \\
\hline Poor $(<7)$ & 121 & 63 & (52.1) & 58 & $(47.9)^{*}$ \\
\hline Good (=7) & 108 & 40 & (37.0) & 68 & (63.0) \\
\hline
\end{tabular}

Hence, a minimum sample size of 111 is required. Data was analysed using the SPSS version 11.0 (SPSS Inc, Chicago, IL, USA). A p value less than 0.05 was considered statistically significant.

\section{RESULTS}

\section{Characteristics of sample}

Most $(68.6 \%)$ participants presented at the clinic for treatment of STD symptoms, those $(31.4 \%)$ asymptomatic were there for an HIV test. During the current visit, 120 $(59.7 \%)$ were diagnosed to have an STD. There were 84 who took a voluntary HIV test and one person was found to be seropositive. The mean age was 34.7 years (range 17-83). The majority $(67.7 \%)$ were Singaporean, while other nationalities included Malaysian (7.7\%), Indian (4.3\%), Bangladeshi $(9.8 \%)$, and Chinese nationals $(5.1 \%)$. Of the respondents, $57.4 \%$ were never married. Three never had any formal education, two had vocational training only, and 46 (19.6\%) had less than 6 years of schooling. Most were skilled (33.2\%) or unskilled $(24.5 \%)$ workers and 12 were unemployed.
Among those who were working, nine $(4.2 \%)$ earned less than US\$285 and $25.8 \%$ earned more than US\$1711 a month. Fifty six $(25.5 \%)$ said that their work required them to travel overseas, with $10.7 \%$ travelling at least once a week and $32.1 \%$ between once to three times a month. Most (74.9\%) drank alcohol, 29.4\% drank at least once a week, $45.5 \%$ drank more than once a week, and $25.1 \%$ were past drinkers. Eighty three $(35.6 \%)$ reported having had a previous STD.

\section{Self reported condom use}

Rates of condom use for this sample were generally high. In total, $83.8 \%$ reported ever using a condom with a sex worker for vaginal sex in the past 6 months, while $72.6 \%$ reported using a condom at the last visit to a sex worker. Rates of condom use for oral sex were lower; $52.6 \%$ in the past 6 months and $38.6 \%$ at last visit. There were $126(55.0 \%)$ respondents who used condoms consistently (that is, $100 \%$ of the time) and $103(45.0 \%)$ were inconsistent condom users. Of note, $16.2 \%(n=37)$ had never used a condom with a sex worker in the past 6 months. 


\section{Sociodemographic, behavioural, and knowledge variables}

Condom use was not significantly associated with age, nationality, or marital status (table 1). Respondents reported a mean of five commercial sex visits in the past 6 months $(\mathrm{SD}=8.42)$ with a median of three. Fewer inconsistent users scored 10 or 11 (of a possible 11) on the STD/HIV transmission knowledge scale than consistent users (table 1). In particular, inconsistent condom users were less likely to have heard of hepatitis B or herpes and were less likely to agree that having one faithful sex partner would prevent STDs. Inconsistent users were more likely to report that they did not know how to use a condom, and they did not know that a condom should be used before penetration or that the teat should be pinched while unrolling the condom. Having experienced problems using condoms was not significantly associated with condom use.

\section{Psychological scales}

Inconsistent condom users scored significantly lower than consistent users on self efficacy (mean $15 \vee 18$ ), condom attitudes (mean $15 v 17$ ) and social norms (mean $13 v 15$ ), and higher on maladaptive behaviours (mean $11 \vee 9$ ) and alcohol impaired decision making (mean $3 \vee 2$ ).

\section{Logistic regression for inconsistent condom use}

These five psychological constructs together with sociodemographic, behavioural, and knowledge variables that were found to be at least marginally significant $(p<0.1)$ in their association with condom use in the past 6 months at the univariate level were entered into a logistic regression model. Age and nationality are covariates in the model. Inconsistent condom use with sex workers in the past 6 months was the dependent variable. Factors associated with inconsistent condom use were poor STD knowledge, more than four commercial sex visits, lower self efficacy, lesser positive social norms, and greater alcohol impaired decision making (table 2). Those with poor compared to good STD knowledge were 3.9 times more likely to be inconsistent users and those who visited sex workers five or more times in the past 6 months were 2.6 times more likely to be inconsistent users. A unit increase in the self efficacy scale decreases the odds of being an inconsistent user by $13 \%$ and a unit increase in the social norms scale decreases the odds of being an inconsistent user by $10 \%$. A unit increase in the alcohol impaired decision making scale increases the odds of being an inconsistent user by $25 \%$.

\section{DISCUSSION}

Of clients attending the STD clinic in Singapore, $45.0 \%$ did not use condoms consistently (that is, $100 \%$ of the time) with sex workers in the 6 months before the interview. The proportion of clients using condoms inconsistently was lower than two other studies conducted in Asia among clinic attendees. The cross sectional survey in Hong Kong reported that inconsistent condom use with sex workers was 52.5\%, ${ }^{11}$ while in Vietnam, only 7\% used condoms consistently with sex workers and $70 \%$ had never used them. ${ }^{12}$ However, in Sydney, Australia, inconsistent condom use among clients of female sex workers was lower $33.2 \% .^{13}$

\section{Factors associated with inconsistent condom use with a sex worker}

This study found that factors significantly associated with inconsistent condom use were poor STD knowledge, frequent commercial sex visits, lower self efficacy, less positive social norms, and higher alcohol impaired decision making. None of the sociodemographic variables was found to be significant in the multivariable analysis.

Those who were poorer in their knowledge about STD transmission were significantly more likely to be inconsistent condom users than those with better knowledge. Although a high percentage $(86 \%)$ of our respondents knew that monogamy was a protective strategy, they visit sex workers who are known to have many sex partners. This shows that knowledge is necessary but insufficient to change behaviour.

Clients who visited a sex worker five or more times in the past 6 months were more likely to be inconsistent condom users. Although this might imply that regular patrons of commercial sex use condoms less often, it could also be an artefact of the measurement. Those who visit sex workers more often would have more opportunities to use or not use condoms and just one unprotected episode in the 6 month time frame would classify him as an inconsistent user. Among a sample of STD clinic attendees in Vietnam, those who visited sex workers frequently were more likely to have experience with condoms ${ }^{12}$; however, there is no indication if these clients were more likely to use condoms consistently.

Self efficacy was found to be a significant factor influencing condom use. Self efficacy relates to one's confidence in performing a behaviour, and an important aspect of this confidence is possessing the skills to execute the behaviour. ${ }^{14}$ Eighteen respondents in this study reported that they did not know or were "not sure" how to use condoms, and they were more likely to be inconsistent users. Hence, condom promotion programmes need to show or describe clearly

Table 2 Logistic regression analysis of inconsistent condom use as a function of statistically significant knowledge, behavioural and psychological variables

\begin{tabular}{|c|c|c|c|c|}
\hline Variable & Regression coefficient $(\boldsymbol{\beta})$ & Wald test & Adjusted $†$ odds ratio & $95 \% \mathrm{Cl}$ \\
\hline \\
\hline \multirow{2}{*}{\multicolumn{5}{|c|}{ STD knowledge }} \\
\hline & & & & \\
\hline 0-9 (poor) & 1.37 & $5.98^{*}$ & 3.92 & (1.31 to 11.68$)$ \\
\hline \multirow{2}{*}{\multicolumn{5}{|c|}{$\begin{array}{l}\text { Behavioural } \\
\text { No of commercial sex visits }\end{array}$}} \\
\hline & & & & \\
\hline $1-4$ & & & 1 & \\
\hline$\geqslant 5$ & 0.97 & $6.51^{*}$ & 2.64 & $(1.25$ to 5.55$)$ \\
\hline \multicolumn{5}{|l|}{ Psychological } \\
\hline Self efficacy & -0.14 & $5.23^{*}$ & 0.87 & $(0.77$ to 0.98$)$ \\
\hline Social norms & -0.10 & $5.72^{*}$ & 0.90 & (0.83 to 0.98$)$ \\
\hline Alcohol impaired decision making & 0.23 & $4.03^{*}$ & 1.25 & (1.01 to 1.56 ) \\
\hline
\end{tabular}


condom use techniques. Clients could be presented with certain scenarios (for example, when a condom is not available) and asked to mentally rehearse how they could still have safer sex in such situations. ${ }^{15}$ Instances of others using condoms consistently should be highlighted. Another method to increase self efficacy is social persuasion-for example, clinic staff can reinforce that the person has the capabilities to master the activity, this might mobilise greater effort from the person to persist in accomplishing the behaviour.

Having social norms that did not encourage consistent condom use with sex workers was significantly associated with inconsistent condom use. Unlike the West, in Asia, commercial sex is often viewed as a social activity, undertaken within a social setting where peer influence has an important role. ${ }^{5}{ }^{16-19}$ Hence, it is not surprising that those who had friends who did not use condoms were more likely to use condoms inconsistently. Social norms were found to be significant correlates of condom use among clients in other studies in Indonesia ${ }^{16}$ and Thailand.$^{18}$ Commercial sex is part of business entertainment in Asia. ${ }^{19}$ Many respondents in this study said they felt obligated to their business clients to entertain them, and this sometimes meant soliciting the services of a sex worker. In such cases, if the business client is against condom use, the individual may feel pressured not to use condoms.

The sex worker is an important part of shaping social norms. Of those whose last encounter was in Singapore, $33.1 \%$ were inconsistent condom users, compared with $61.5 \%$ whose last encounter was overseas $(\mathrm{p}<0.001)$. This suggests that situational factors, such as brothel policies and condom assertiveness behaviour on the part of sex workers, may be important determinants of consistent condom use. ${ }^{20} 21$

Inconsistent users said that they were more likely to forget to use a condom when they were drunk than consistent users. This result is not surprising as alcohol affects judgment and thereby promotes risky sexual practices. Studies have shown that intoxicated respondents had weaker intentions to use a condom. ${ }^{22}$ Alternatively, many men use condoms even while intoxicated and clients we interviewed may be using intoxication as a ready and widely accepted excuse for not using condoms consistently. ${ }^{23}$

\section{Limitations}

This study is cross sectional and the associations reported cannot be considered causal. The study sample consists of clinic attendees. Hence, study findings cannot be generalised to the actual population of clients who visit sex workers or the actual prevalence of condom use among clients of sex workers. However, it may not be practical to truly randomly sample such a population. Those who did not use condoms and developed symptoms, those who felt guilty about going to sex workers after the fact and those who felt a heightened susceptibility to HIV are over-represented in this sample. Clients who use condoms consistently are likely to be underrepresented.

There were $29.4 \%$ of respondents who said that there were certain people who could not get STD, they were usually referring to categories of people who are known to be celibate (for example, monks). The intention of the question was to tap any maladaptive thinking that they may ascribe to, but some respondents may have understood the question in a different way from what the researcher intended. Poor measurement of construct is a possible bias in this study. A survey among male commercial sex workers in Bali, Indonesia also found it difficult to get respondents to rate beliefs. ${ }^{24}$ This is the challenge facing researchers in this region where respondents are not as exposed to research as in the West. This study found that phrasing items as questions and using smiley faces improved the internal consistency of the scales.

\section{Implications}

Condom promotion programmes targeting clients of sex workers should stress that HIV and STDs are preventable and consistent condom use is the best preventive strategy. Such a programme should include information on STD/HIV transmission, address existing misconceptions, and give assurances of condom effectiveness in STD/HIV prevention. The programme would need to include skills training in condom use with a focus on improving client's self efficacy in using condoms. For consistent condom use with sex workers to be part of the social norm, interventions for sex workers and brothel managers must also be implemented.

\section{ACKNOWLEDGEMENTS}

The authors would like to thank the staff at DSC for their support of the project. The project was supported in part by National Medical Research Council grant 960358.

\section{CONTRIBUTORS}

SW, study design, interviews, data analysis and interpretation, writing of the manuscript; $\mathrm{MB}$, study design, data analysis and interpretation, writing of the manuscript; MLW, study design, data analysis and interpretation, writing of the manuscript; TJ, interviews, review of the manuscript; RC, study design, review of the manuscript.

\section{Authors' affiliations}

S Wee, Department of Community, Occupational and Family Medicine, Faculty of Medicine, National University of Singapore, Singapore

M E Barrett, Department of Social Work and Psychology, Faculty of Arts and Social Sciences, National University of Singapore, Singapore

W M Lian, Department of Community, Occupational and Family Medicine, Faculty of Medicine, National University of Singapore, Singapore

T Jayabaskar, Department of Community, Occupational and Family Medicine, Faculty of Medicine, National University of Singapore, Singapore

K W R Chan, Department of Sexually Transmitted Infections, National Skin Centre, Singapore

\section{REFERENCES}

1 Family Health International. What drives HIV in Asia? A summary of trends in sexual and drug-taking behaviours. 2001. (Available at www.fhi.org/NR/ rdonlyres/eikydmvwwopux 5 pvmppvhhgrzbui4e5dumbnqu6k2qzifubi5gmno dk6m5vh6776vshohs6upt2lzn/whatdriveshivnasiabsspdf, accessed 15 September 2003).

2 Monitoring the AIDS Pandemic Network. (MAP). The status and trends of HIV/AIDS/STI epidemics in Asia and the Pacific (MAP provisional report, 4 October). 2001. (Available at www.unaids.org/hivaidsinfo/statistics/MAP, accessed 20 November 2001).

3 Ministy of Health (MOH) Singapore. HIV infection and AIDS in Singapore, 2001. Epidemiological News Bulletin 2002;28:61-5.

4 Heng BH, Lee HP, Kok LP, et al. A survey of sexual behaviour of Singaporeans. Ann Acad Med Singapore 1992;21:723-9.

5 Lowndes $\mathrm{CM}$, Alary M, Meda H, et al. Role of core and bridging groups in the transmission dynamics of HIV and STIs in Cotonou, Benin, West Africa. Sex Transm Infect 2002;78(Suppl 1):i69-77.

6 Thomas DB, Ray RM, Kuypers J, et al. Human papillomaviruses and cervical cancer in Bangkok. III. The role of husbands and commercial sex workers. Am J Epidemiol 2001;153:740-8.

7 Ajzen I. The theory of planned behavior. Organizational Behavior and Human Decision Processes 1991;50:179-211.

8 Sheeran P, Taylor S. Predicting intentions to use condoms: a meta-analysis and comparison of the theories of reasoned action and planned behaviour. J Appl Soc Psychol 1999;29:1624-75.

9 Rogers RW, Prentice-Dunn S. Protection motivation theory. In: Gochman DS, ed. Handbook of health behavior research. 1: Personal and social determinants. New York: Plenum Press, 1997:113-32.

10 Tabachnick BG, Fidell LS. Using multivariate statistics. Boston, USA: Allyn and Bacon, 2001.

11 Wong KH, Lee SS, Lo YC, et al. Condom use among female commercial sex workers and male clients in Hong Kong. Int J STD AIDS 1994;5:287-9.

12 Thuy NT, Lindan CP, Phong TH, et al. Predictors of visits to commercial sex workers by male attendees at sexually transmitted disease clinics in southern Vietnam. AIDS 1999;13:719-25. 
13 Coughlan E, Mindel A, Estcourt CS. Male clients of female commercial sex workers: HIV, STDs and risk behaviour. Int J STD AIDS 2001; 12:665-9.

14 Bandura A. Perceived self-efficacy in the exercise of control over AIDS infection. Evaluation and Program Planning 1990;13:9-17.

15 VanOss MB, Gomez CA, Tschann JM, et al. Condom use in unmarried Latino men: a test of cultural constructs. Health Psychology 1997;16:458-67.

16 Ford K, Wirawan DN, Muliawan P. Social influence, AIDS/STD knowledge and condom use among male clients of female sex workers in Bali. AIDS Educ Prev 2002;14:496-504.

17 Maticka-Tyndale E, Elkins D, Haswell-Elkins M, et al. Contexts and patterns of men's commercial sexual partnerships in Northeastern Thailand: implications for AIDS prevention. Soc Sci Med 1997;44:199-213.

18 Vanlandingham MJ, Suprasert S, Grandjean N, et al. Two views of risky sexual practices among northern Thai males: the health belief model and the theory of reasoned action. J Health Soc Behav 1995;36:195-212.
19 Vanlandingham MJ, Knodel J, Saengtienchai C, et al. In the company of friends: peer influence on Thai male extramarital sex. Soc Sci Med 1998;47:1993-2011.

20 Sedyaningsih-Mamahit ER. Clients and brothel managers in Kramat Tunggak, Jakarta, Indonesia: interweaving qualitative with quantitative studies for planning STD/AIDS prevention programs. Southeast Asian J Trop Med Public Health 1997;28:513-24.

21 Sneed CD, Morisky DE. Applying the theory of reasoned action to condom use among sex workers. Soc Behav Pers 1998;26:317-27.

22 Conner M. Graham S, Moore B. Alcohol and intentions to use condoms: applying the theory of planned behaviour. Psychology and Health 1999;14:795-812.

23 Leigh BC. Alcohol and condom use: a meta-analysis of event-level studies. Sex Transm Dis 2002;29:476-82.

24 Ford $\mathrm{K}$, Wirawan DN, Fajans $\mathrm{P}$, et al. AIDS knowledge, risk behaviors, and factors related to condom use among male commercial sex workers and male tourist clients in Bali, Indonesia. AIDS 1995;9:751-9.

\section{Clinical Evidence-Call for contributors}

Clinical Evidence is a regularly updated evidence based journal available worldwide both as a paper version and on the internet. Clinical Evidence needs to recruit a number of new contributors. Contributors are health care professionals or epidemiologists with experience in evidence based medicine and the ability to write in a concise and structured way.

\section{Currently, we are interested in finding contributors with an interest in}

the following clinical areas:

Altitude sickness; Autism; Basal cell carcinoma; Breast feeding; Carbon monoxide poisoning; Cervical cancer; Cystic fibrosis; Ectopic pregnancy; Grief/bereavement; Halitosis; Hodgkins disease; Infectious mononucleosis (glandular fever); Kidney stones; Malignant melanoma (metastatic); Mesothelioma; Myeloma; Ovarian cyst; Pancreatitis (acute); Pancreatitis (chronic); Polymyalgia rheumatica; Post-partum haemorrhage; Pulmonary embolism; Recurrent miscarriage; Repetitive strain injury; Scoliosis; Seasonal affective disorder; Squint; Systemic lupus erythematosus; Testicular cancer; Varicocele; Viral meningitis; Vitiligo However, we are always looking for others, so do not let this list discourage you.

\section{Being a contributor involves:}

- Appraising the results of literature searches (performed by our Information Specialists) to identify high quality evidence for inclusion in the journal.

- Writing to a highly structured template (about 2000-3000 words), using evidence from selected studies, within 6-8 weeks of receiving the literature search results.

- Working with Clinical Evidence Editors to ensure that the text meets rigorous epidemiological and style standards.

- Updating the text every eight months to incorporate new evidence.

- Expanding the topic to include new questions once every 12-18 months.

If you would like to become a contributor for Clinical Evidence or require more information about what this involves please send your contact details and a copy of your CV, clearly stating the clinical area you are interested in, to Claire Folkes (cfolkes@bmigroup.com).

\section{Call for peer reviewers}

Clinical Evidence also needs to recruit a number of new peer reviewers specifically with an interest in the clinical areas stated above, and also others related to general practice. Peer reviewers are health care professionals or epidemiologists with experience in evidence based medicine. As a peer reviewer you would be asked for your views on the clinical relevance, validity, and accessibility of specific topics within the journal, and their usefulness to the intended audience (international generalists and health care professionals, possibly with limited statistical knowledge). Topics are usually 2000-3000 words in length and we would ask you to review between 2-5 topics per year. The peer review process takes place throughout the year, and our turnaround time for each review is ideally 10-14 days.

If you are interested in becoming a peer reviewer for Clinical Evidence, please complete the peer review questionnaire at www.clinicalevidence.com or contact Claire Folkes(cfolkes@bmigroup.com). 